\title{
REGENERATION AND REUSE OF BIOMATERIAL FOR THE REMOVAL OF CADMIUM IONS FROM WASTE WATER
}

\section{Jagjit Kour}

Journal of Institute of Science and Technology

Volume 21, Issue 1, August 2016

ISSN: 2469-9062 (print), 2467-9240(e)

Editors:

Prof. Dr. Kumar Sapkota

Prof. Dr. Armila Rajbhandari

Assoc. Prof. Dr. Gopi Chandra Kaphle

JIST, 21 (1), 90-94 (2016)

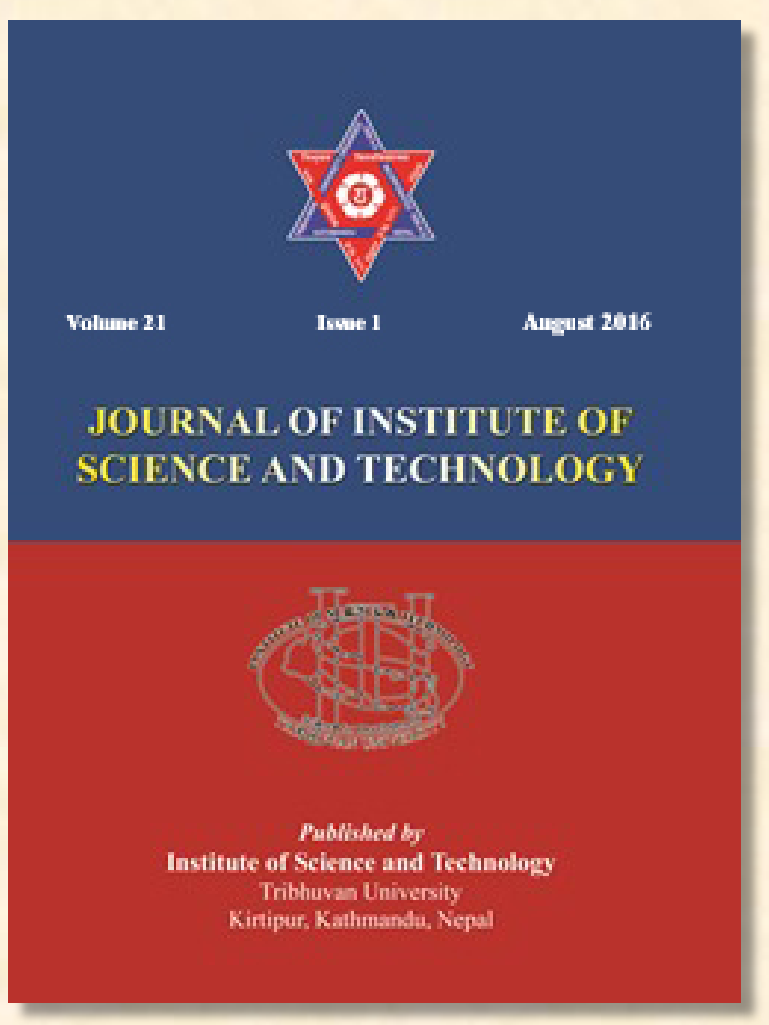

Published by:

Institute of Science and Technology

Tribhuvan University

Kirtipur, Kathmandu, Nepal 


\title{
REGENERATION AND REUSE OF BIOMATERIAL FOR THE REMOVAL OF CADMIUM IONS FROM WASTE WATER
}

\author{
Jagjit Kour \\ Department of Chemistry, Tri-Chandra Multiple Campus, Tribhuvan University, Kathmandu, Nepal \\ Corresponding email: jagjit_kour@hotmail.com
}

\begin{abstract}
The nitrogen functionalized biomaterial is used for the adsorption of $\mathrm{Cd}$ (II) from waste water. The application and possibility of regeneration and reuse of functionalized biomaterial were evaluated with adsorption desorption experiments. Cd (II) loaded biomaterial was eluted with sodium hydroxide, nitric acid, and hydrochloric acid. Among them $0.1 \mathrm{M}$ nitric acid gave the most effective result releasing about $90 \%$ of metal ions onto the solution in six successive cycles. The result suggests the efficiency and applicability of functionalized biomaterial as a potential biosorbent in the removal of Cd (II) from waste water.
\end{abstract}

Keywords: Desorption, Adsorption, Functionalized biomaterial, Cadmium Regeneration and reuse

\section{INTRODUCTION}

Many industrial effluents containing toxic metal ions are removed with coagulation, precipitation, reverse osmosis, ultra filtration, ion-exchange and ozonolysis. However these techniques have limitation like incomplete metal removal, production of huge amount of toxic sludge, and requirement of large amount of chemicals and energy, especially when the concentration of toxic heavy metals is low. This has caused a paradigm shift to biosorption where treatment of waste water occurs by the use of biomaterial. Biomaterials are the byproduct from poultry, fishery or agriculture and many more. They are highly efficient, renewable, low cost and can be regenerated (Kratochvil \& Volesky 1998). They are the alternative to man-made ion-exchange resins (An et al. 2005). The biomaterial of lignocellulosic nature is found to be one of the efficient biomaterial for the removal of toxic heavy metals from waste water. Since raw biomaterials show very low adsorption of metal ions, they are functionalized with different functional groups like carboxylic acid, sulfonic acid, amine, amide, phosphoric acid (Shankar et al. 2007), Xanthate (Homagai et al. 2011) to enhance the adsorption capacity. The biosorption process is cost effective, efficient, requires minimum chemical and also minimizes the toxic sludge production. During the regeneration of the biomaterial, the metal ions extracted from the liquid phase can be recovered and the regenerated biomaterial can be reused for adsorption experiments, which also minimizes the process cost.

Cadmium (II) is one of the toxic heavy metal ions present in waste water from different sources like, gasoline, metal pipes, fertilizers, dental alloys, batteries, candy, colas, copper refineries, fungicides, paint, pesticides, processed foods, soft drinks, pharmaceutical and recreational drugs (Dojlido \& Best 1993). It can cause mental retardation, bronchitis, and cancer. The most severe form of Cd toxicity in human is itai-itai, a disease characterized by excruciating pain in the bone. Other health implication of $\mathrm{Cd}$ in human includes kidney dysfunction, emphysema, and testicular atrophy (Kadirvelu \&Namasivayam 2000). Chronic exposure in high levels results in death. The maximum permissible limit of $\mathrm{Cd}$ in drinking water is $0.003 \mathrm{mg} / \mathrm{L}$ according to WHO standard. Therefore this toxic metal ion must be removed before discharged into water bodies.

In the present study, functionalized biomaterial obtained from Desmostachya bipinnata is used for the removal of $\mathrm{Cd}$ (II) and its loading capacity is measured. The possibility of regeneration and reuse of the biomaterial is studied with desorption experiment to evaluate its effectiveness (Homagai et al. 2011). 


\section{MATERIALS AND METHODS}

The entire chemicals used in this work were of analytical grade. Powder of Desmostachya bipinnata (Kush plant) was functionalized with hydrazine monohydrate to introduce nitrogen functional group in the biomaterial with one step reaction, which is one of the most effective chelating group ( Yoshitake et al. 2002; $\mathrm{Ng}$ et al. 2002) and used for the adsorptive removal of cadmium metal ions from waste water. The detail of the preparation procedure has been published in previous paper (Kour et al. 2013).

The surface morphologies of functionalized and metal loaded biomaterial were analyzed with the help of S-3000 N Scanning Electron Microscope (SEM) of HITACHI, Japan. The types of functional groups present on the biomaterial were analyzed using Diffuse Reflectance Fourier Transform Infrared (DRFTIR) Spectroscopy (Harrick scientific corporation) at frequency range of 4000 to $500 \mathrm{~cm}^{-1}$. The $\mathrm{pH}$ of the sample solution was measured with $\mathrm{pH}$ meter (Hanna instrument). Concentration of metal ions present in the solution was measured with ICP-AES (Inductively-Coupled Plasma Atomic Emission Spectrophotometer, SPECTRO, Analytical Instrument, Kleve, Germany).

Batch adsorption experiments were carried out to measure the effect of $\mathrm{pH}$, loading capacity, efficiency and reusability of the functionalized biomaterial for the remove of $\mathrm{Cd}$ (II) from waste water.

Effect of $\mathrm{pH}$ was studied at $50 \mathrm{mg} / \mathrm{l}$ concentration of metal ions as the function of $\mathrm{pH}$ from 1-7. All the experiments were carried out in $50 \mathrm{ml}$, Erlenmeyer flasks taking $25 \mathrm{mg}$ of functionalized biomaterial with $20 \mathrm{ml}$ of $\mathrm{Cd}$ (II) solution. The $\mathrm{pH}$ of $\mathrm{Cd}$ (II) was maintained with dilute nitric acid and sodium hydroxide solutions. The flasks were agitated in a shaker at room temperature at $150 \mathrm{rpm}$ for $24 \mathrm{~h}$ to attain equilibrium. After $24 \mathrm{~h}$, the solutions were filtered and their equilibrium concentrations were measured.

Loading capacity was evaluated with fixed dose of biomaterial $(25 \mathrm{mg})$ and metal solution $(20 \mathrm{ml})$ of different concentration from $25-1000 \mathrm{mg} / \mathrm{l}$ at optimum $\mathrm{pH}$ value.

The applicability of the metal loaded biomaterial as an efficient adsorbent depends not only on the loading capacity, it also depends on the desorption performance, which finally leads to its reusability (Biswas et al. 2008). Batch desorption experiments were carried out to evaluate the efficiency and reusability of functionalized biomaterial (Shrestha et al. 2013). In the present study metal ions were adsorbed on to the surface of the functionalized biomaterial. The experiment was carried out with $80 \mathrm{ml} \mathrm{Cd}$ (II) solution of $100 \mathrm{mg} / \mathrm{L}$ together with $100 \mathrm{mg}$ of functionalized biomaterial in a flask. The flask was shaken for $6 \mathrm{~h}$ at $150 \mathrm{rpm}$ to attain the equilibrium. Then the solution was filtered and concentration of metal ions present in the solution was measured. This metal adsorbed biomaterial was desorbed with three different types of eluting agents like sodium hydroxide, hydrochloric acid and nitric acid at different concentrations $(0.5 \mathrm{M}, 0.2 \mathrm{M}$ and $0.1 \mathrm{M}$ ) separately (Ayyappan et al. 2005; Chergui et al. 2007). The flasks were shaken for $3 \mathrm{~h}$ and were filtered. The concentration of metal ions was measured. This is the amount of metal ions desorbed from the biomaterial. After the first cycle of adsorption-desorption experiment, the biomaterial was washed with distilled water and dried in an air oven at $70^{\circ} \mathrm{C}$ for $24 \mathrm{~h}$. This regenerated biomaterial was repeatedly used for another five cycles of adsorption-desorption experiment.

\section{RESULTS AND DISCUSION}

The SEM image of the surface of functionalized biomaterial was uneven and porous, as shown in Fig.1 (a). It is due to the grafting of the nitrogen functional group on the surface of the biomaterial which enhances the metal ion sorption (Kour et al. 2013).

After performing batch experiment for the adsorption of Cd (II), the SEM image of Cd (II) loaded functionalized biomaterial was also studied as shown in Fig. 1 (b). It was compared with the functionalized biomaterial before adsorption of $\mathrm{Cd}$ (II). The uneven and porous surface of the functionalized biomaterial was changed to even and smooth surface with bright image indicating the adsorption of metal ions onto functionalized biomaterial.

DRFTIR spectra were used to identify the types' of functional groups present in a molecule (Jin \& Bai 2002; Sankararamakrishnan \& Sanghi 2006). A broad peak around $3500 \mathrm{~cm}^{-1}$ in functionalized biomaterial was observed, which may be due to the overlapping of the hydroxyl group with nitrogen functional group. The peak at around $1650 \mathrm{~cm}^{-1}$ was observed in functionalized biomaterial which may be due to $\mathrm{N}-\mathrm{H}$ bending vibration of amines (Shriner et al. 1998). This further indicates that 
large number of nitrogen functional groups has been grafted into the surface of biomaterial.

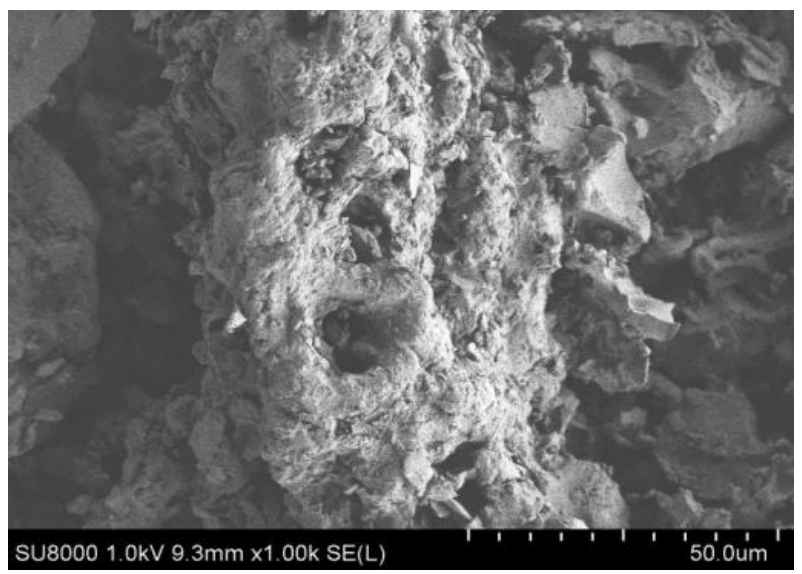

(a)

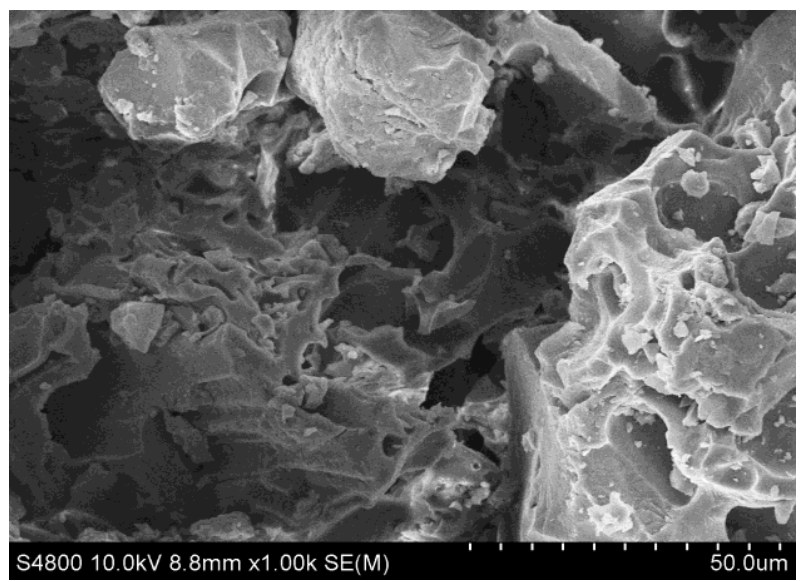

(b)

Fig.1. SEM of D.bipinnata (a) Functionalized (b) Cd (II) loaded biomaterial.

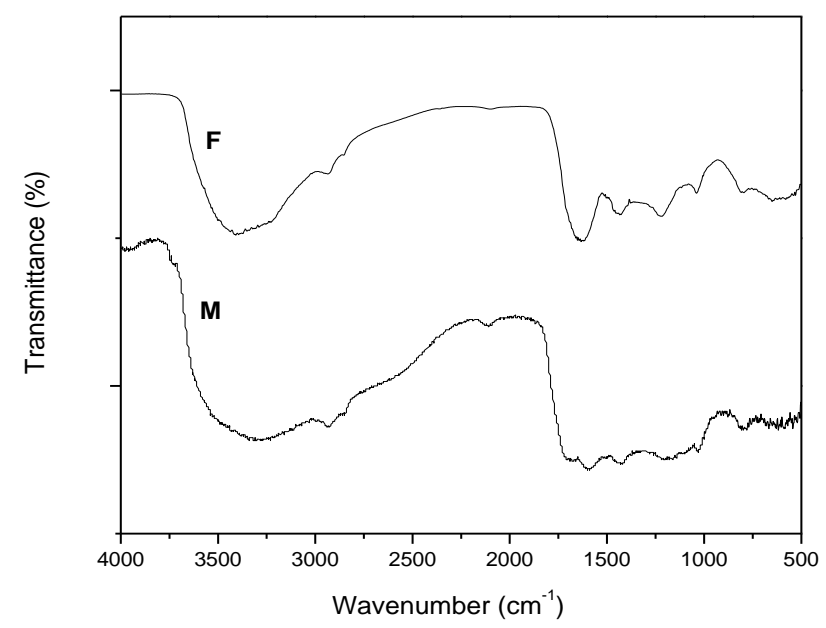

Fig. 2. DRFTIR of D.bipinnata (F) Functionalized (M) Cd (II) loaded biomaterial.
DRFTIR spectra of Cd (II) loaded functionalized biomaterial was also studied. The peaks were broadened and shifted at the lower wave number and reduction in transmittance was also observed when compared with functionalized biomaterial as shown in Fig. 2. It also suggests that the nitrogen functional groups are involved in the adsorption of Cd (II) (Jin \& Bai 2002; Thirumavalavan et al. 2010).

The optimum $\mathrm{pH}$ for the $\mathrm{Cd}$ (II) was found at $\mathrm{pH} 6$. The maximum loading capacity (q $\mathrm{mg} / \mathrm{g}$ ) of functionalized biomaterial for the Cd (II) was found to be $83.33 \mathrm{mg} / \mathrm{g}$.

Experiments on adsorption desorption and regeneration of biomaterial was performed with batch method. In this study three types of eluting agents like sodium hydroxide, hydrochloric acid and nitric acid were used. The result indicated that, $0.1 \mathrm{M}$ nitric acid was found to be most effective eluting agent among three of the eluting agents releasing the $\mathrm{Cd}$ (II) adsorbed on to the functionalized biomaterial. Fig. 3 shows the loading capacity $(\mathrm{q} \mathrm{mg} / \mathrm{g})$ and the desorption cycles of the biomaterial where as Fig. 4 shows the percentage desorption for the Cd (II) in six cycles.

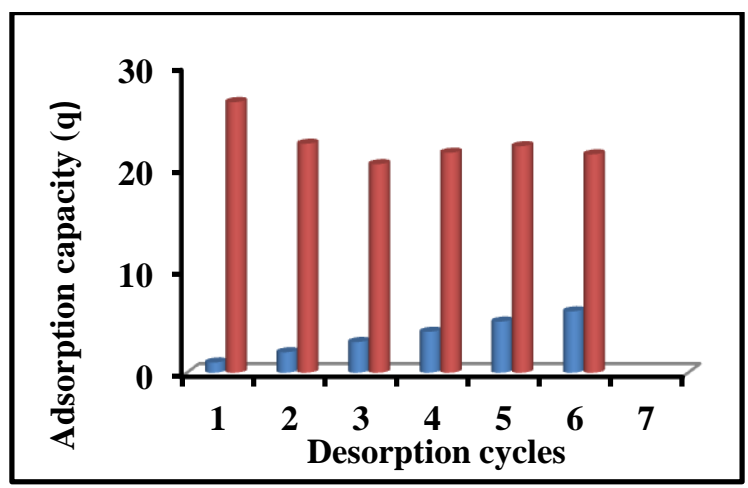

Fig. 3. Desorption and reuse of biomaterial for adsorption of $\mathrm{Cd}(\mathrm{II})$.

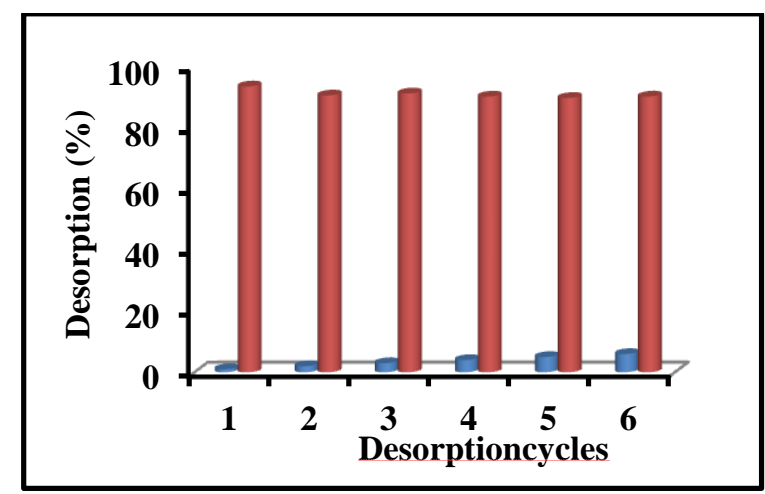

Fig. 4. Percentage desorption of $\mathrm{Cd}(\mathrm{II})$ for six successive cycles. 
The result revealed that above $93 \% \mathrm{Cd}$ (II) were desorbed from the biomaterial in first cycle and decreased up to $89.9 \%$ in fifth cycle which was increased to $90.3 \%$ in sixth cycle. More over the elution with nitric acid once again suggested that the Cd (II) adsorption on functionalized biomaterial was caused mainly by chemical adsorption. The release of adsorbed Cd (II) could be attributed to the relatively weak energy of interaction between metal ions and functionalized biomaterial (Kong et al. 2014). The adsorption capacity remained relatively constant in subsequent cycles, indicating the chemical stability of the biomaterial. It also indicated that the metal adsorbed biomaterial can be regenerated almost completely with $0.1 \mathrm{M}$ nitric acid, and the biomaterial can be repeatedly used for metal ions adsorption, thereby minimizing the cost for the adsorption process. The regeneration and reuse of biomaterial suggests the efficiency, effectiveness, and application for the removal of $\mathrm{Cd}$ (II) from waste water as ecofriendly material.

Table 1. Loading capacity and \% Desorption cycle for $\mathrm{Cd}$ (II)

\begin{tabular}{|c|c|c|}
\hline $\begin{array}{c}\text { No. of } \\
\text { Cycles }\end{array}$ & $\begin{array}{c}\text { Loading capacity } \\
(\mathbf{m g} / \mathbf{g})\end{array}$ & $\begin{array}{c}\% \\
\text { Desorption }\end{array}$ \\
\hline 1 & 26.48 & 93.65 \\
\hline 2 & 22.40 & 90.71 \\
\hline 3 & 20.40 & 91.37 \\
\hline 4 & 21.52 & 90.33 \\
\hline 5 & 22.16 & 89.90 \\
\hline 6 & 21.36 & 90.36 \\
\hline
\end{tabular}

\section{CONCLUSIONS}

The regeneration and reusablity of functionalized biomaterial was studied for Cd (II). The eluting agents used in this experiment were sodium hydroxide, hydrochloric acid and nitric acid. Among them $0.1 \mathrm{M}$ nitric acid gave the best result which desorbed more than $90 \%$ of metal ion from the functionalized biomaterial. It also indicates the chemical stability of the biomaterial. The regeneration and reuse of biomaterial minimize the cost for the adsorption process as well as reduces the volume of waste material making the process environment friendly, effective and economic. The functionalized biomaterial prepared from Dismostachya bipinnata showed its applicability as a potential biomaterial in the adsorptive removal of Cd (II) from waste water.

\section{ACKNOWLEDGEMENTS}

The author would like to acknowledge Central Department of Chemistry, Tribhuvan University, Kathmandu and Department of Agricultural Biotechnology, Padua University, Legnaro, Italy for providing laboratory facilities to carry out this research work. The author is grateful to Dr. Masimo Cagnin for ICP-AES, Dr. Antonella Glesenti for DRFTIR analysis from Padua University and Prof. Dr. Amar Prasad Yadav for SEM images from NEMS, Japan.

\section{REFERENCES}

An. H. K., Park B. Y. and Kim D. S. 2001. Crab shell for the removal of heavy metals from aqueous solution. Water Research 35(15): 3551-3556.

Ayyappan, R., Carmalin Sophia, A., Swaminathan, K., and Sandhya, S. 2005. Removal of Pb(II) from aqueous solution using carbon derived from agricultural wastes. Process Biochemistry 40: 1293-1299.

Biswas, B. K., Inoue, K., Ghimire, K. N., Harada, H., Ohto, K., Kawakita, H. 2008. Removal and recovery of Phosphorus from water by means of adsorption onto orange waste gel loaded with zirconium. Bioresource Technology, 99: 8685-8690.

Chergui, A., Bakhnter, M. Z., Chahboub, A., Haddoum, S., Selania, A., and Junter, G. A. 2007. Simultaneous biosorption of $\mathrm{Cu}^{2+}, \mathrm{Zn}^{2+}$ and $\mathrm{Cr}^{2+}$ from aqueous solution by Streptomyces rimosus biomass. Desalination 206: $179-184$.

Dojlido, J. R., and Best, G. A. 1993. Chemistry of water and water pollution. Ellis Horwood Ltd, Great Britain, pp 65-121.

Homagai, P. L., Ghimire, K. N., and Inoue, K. 2011. Preparation and characterization of charred xanthated sugarcane bagasse for the separation of heavy metals from aqueous solutions. Separation Science and Technology 46(2): 330-339.

Jin, L. and Bai, R. B. 2002. Mechanisms of lead adsorption on chitosan/PVA hydrogel beads. Langmuir. 18: $9765-9770$.

Kadirvelu, K., and Namasivayam, C. 2000. Agricultural by-product as metal adsorbent: sorption of lead(II) from aqueous solution onto coirpith carbon. Environmental Technology, 21(10): 1091-1097. 
Kong, W., Ren, J., Wang, S., and Chen, Q. 2014. Removal of heavy metals from aqueous solutions using Acrylic-modified Sugercane Bagasse- based Adsorbents: Equlibrium and Kinetic Studies. Bio Resources 9(2): 3184-3196.

Kour, J., Homagai, P. L ., Cagnin,M., Masi, A., Pokhrel, M. R., and Ghimire, K.N. 2013. Adsorption of $\mathrm{Cd}$ (II), $\mathrm{Cu}$ (II) and $\mathrm{Zn}$ (II) From Aqueous Solution onto Nitrogen Functionalized Desmostachya bipinnata , Journal of Chemistry, 2013: 1-7.

Kratochvil, D. and Volesky, B. 1998. Advances in biosorption of heavy metals. Trends in Biotechnology 16: 291-300.

Ng, J.C.Y., Cheung, W.H. and Mckay, G.1981. Equilibrium studies of the sorption of $\mathrm{Cu}$ (II) ions onto chitosan. J. Colloid Interface Sci. 255: 64-74.

Sankararamakrishnan, N. and Sanghi, R. 2006. Preparation and characterization of a novel xanthated chitosan. Carbohydrate Polymer, 66: $160-167$.

Shankar, S., Vijayalakshmi, S., Subramanian, S., Rajagopan, S. and Kaliyappan, T. 2007.
Synthesis and chelation properties of a new polymeric ligand derived from 8-hydroxy-5azoquinoline hydroxybenzene. European Polymer Journal, 43: 4639-4646.

Shrestha B., Kour J., Homagai P.L., Pokhrel M.R. and Ghimire K.N. 2013. Surface modification of the Biowaste for the purification of wastewater contaminated with Toxic heavy metals- Lead and Cadmium. Advances in Chemical Engineering and Science 3: 178-184.

Shriner, R. L., Hermann, C. K. F., Morrill, T. C., Curtin, D. Y. and Fuson, R. C. 1998. The Systematic Identification of Organic Compounds, $7^{\text {th }}$ Ed. Wiley, New York, pp 324.

Thirumavalavan, M., Lai, Y. L., Lin, L. C. and Lee, J.F. 2010. Cellulose- Based Native and Modified Fruit Peels for the Adsorption of Heavy Metal Ions from aqueous Solution: Langmuir Adsorption Isotherms. $J$ of Chemical \& Engineering Data, 55: 11861192.

Yoshitake H., Yokoi T. and Tatsumi T. 2002. Adsorption of chromate and arsenate by amino-functionalized MCM-41 and SBA-1. Chem. Mater., 14(11): 4603-4610. 